\title{
The Development of Social Media Guidelines for Psychologists and for Regulatory Use
}

\author{
Kenneth Drude ${ }^{1}$ (D) $\cdot$ Karen Messer-Engel ${ }^{2}$ \\ Received: 5 September 2020 / Revised: 5 September 2020 / Accepted: 20 October 2020 / Published online: 2 November 2020 \\ (C) Springer Nature Switzerland AG 2020
}

\begin{abstract}
The Association of State and Provincial Psychology Boards, the national organization representing psychology regulatory/ licensing boards in Canada and the USA, recently developed social media guidelines that are being recommended for use by its member boards. The purposes of the guidelines were to provide guidance to psychology regulatory boards both countries in identifying and communicating what are considered appropriate and inappropriate uses of social media and to promote consistency and clarity about this across jurisdictions. The process involved reviewing the professional literature, relevant guidelines, standards, current laws, and regulations. The guidelines developed include guidelines about confidentiality, informed consent, risk management, competence, multiple relationships, professional conduct, security of information, personal use of social media, and regulatory board use of social media. Major challenges and limitations in accomplishing this task are identified and discussed.
\end{abstract}

Keywords Social media $\cdot$ Guidelines $\cdot$ Regulation $\cdot$ Standards $\cdot$ Ethics

\section{Introduction}

Over the past decade, health profession regulatory boards and national professional organizations have increasingly turned their attention to how social media ${ }^{1}$ is being used by their licensees and members. For regulatory boards, this has frequently been in response to client complaints about licensee use of social media that has been adjudicated to be professionally inappropriate (Drude 2016, "Feedback", 2012, Greysen et al. 2012). Although other health and behavioral health professions have developed social media guidelines or standards for their members that provide some guidance for their regulatory boards, psychology has not yet moved beyond the minimal guidance of "be careful".

\footnotetext{
${ }^{1}$ Social media is defined in this paper as an umbrella term that includes the various activities that 872 integrate technology and social interaction such as texting, email, instant messaging, websites, 873 microblogging (e.g., Twitter), and all forms of social networking.
}

Kenneth Drude

kenneth.drude@psy.ohio.gov

Karen Messer-Engel

registrar.skcp@sasktel.net

1 Ohio Board of Psychology, Columbus, OH, USA

2 Saskatchewan College of Psychologists, Regina, Canada
For the most part, the profession of psychology and its regulatory community have not developed specific standards or guidelines for the use of social media by psychologists, rather relying upon its ethical codes (APA 2017, CPA ethics 2017) and telepsychology guidelines (APA 2013; CPA 2020; ACPRO 2011) in providing guidance and in considering complaints that focus on or include social media use by members of the profession. The exception to this scarcity has been the recent development and adoption of social media guidelines by the Oregon Board of Psychology (2018). Although the American Psychological Association initiated drafting social media guidelines for psychologists in 2019 (APA 2020), to the authors' knowledge these have not progressed beyond an initial draft for internal comment. The CPA interim telepsychology guidelines were recently revised in 2020 and are general and congruent with the ethical principles, and do not specifically address the issue of social media use by members of the profession.

The Association of State and Provincial Psychology Boards is a member organization comprised of the regulatory bodies for the psychology in Canada, the United States (U.S.) and its territories whose mission is "to support member jurisdictions in fulfilling their responsibility in regulation" (ASPPB 2020). The ASPPB supports competency and excellence in the regulation of the profession. The member boards of the ASPPB individually responded 
to questions about social media use by licensees but unfortunately there appears to be no consensus or clear guidance about this issue. Some of the identified social media use issues psychology boards have raised include concerns about confidentiality, professional boundaries, and informed consent. Specifically, concerns have been voiced about the use of non-secure applications, networks, and platforms; engaging in personal and nonprofessional messaging; inconsistent documentation of clinically related social media communications; and posting to social media networks. Issues that confound the regulatory board response to questionable or unprofessional uses of social media by psychologists include: a lack of clarity and consensus about what "social media" actually includes as this communication modality is rapidly evolving, uncertainty about personal and professional boundaries and when they inappropriately intersect, and that the available guidance about professional uses of social media is largely aspirational and open to individual interpretation about how to practically apply it.

In response to an increasing need for greater regulatory clarity and consistency in providing guidance to psychologists, the ASPPB established a Social Media Task Force (SMTF) in late 2017. The two major tasks assigned to the task force were to (1) create guidelines for psychology regulatory boards in Canada and the U.S. and its territories regarding the use of social media by psychologists and (2) to consider/make recommendations in regard to regulatory language regarding the use of social media by psychologists. The SMTF is composed of representatives of Canadian and United States psychology boards, most of whom also have experience in clinical service delivery, and some with experience in the education and training of psychologists.

The SMTF met from 2018 to 2020 in person and via teleconferencing and was in the process of finalizing a report and guidelines at the time this paper was written. This paper describes the process used by the task force to develop social media guidelines, its findings, the draft guidelines, and identifies and discusses some of the challenges and limitations in establishing and applying guidelines.

\section{Methods/Results}

The scope of the SMTF charges required consideration of both the professional and personal uses of social media by psychologists given the lack of consensus and clarity about boundaries in the use of this modality. Prior to beginning its work, the SMTF identified the following responsibilities of the regulatory boards that would guide it in developing guidelines:
- To be clear with licensees about regulatory expectations in terms of their use of social media, including caution regarding its use in both their private and professional lives

- To be clear with the public about what is acceptable practice and what they can expect from their psychologist, and from a technologically-based service

- To be proactive in the regulation of social media use by members of the profession

- To as much as possible minimize "gray" areas that are open to individual interpretation

- To encourage consistency between jurisdictions in terms of regulatory standards, process, and philosophy

- To work collaboratively with other jurisdictions to support safe and accountable social media/technology-based practice within and between jurisdictions in the public interest

\section{Survey of Regulatory Boards ${ }^{2}$}

The SMTF's work began in earnest in July through August 2018 with an online survey of ASPPB member jurisdictions regarding their concerns and experiences in regulating the profession's use of technology in general and social media in particular. ASPPB has 64 member jurisdictions, $44 \%$ of whom responded to the survey. Regulators were asked to identify their most significant concerns from a prescribed list. The areas of concern most endorsed by respondents were in relation to the provision of services to clients (84\%), advertising (63\%), and supervision $(53 \%)$. Respondents indicated concerns about licensee use of social media/telecommunication in the following practice competency areas: confidentiality (91\%), security $(83 \%)$, boundaries $(74 \%)$, and record keeping $(71 \%)$. These areas correspond to those commonly reported to the ASPPB Disciplinary Data System by the regulatory boards and are issues for which licensees are often formally disciplined.

More than half (58\%) of the respondents reported that they had received complaints about, or that included the social media use of licensees, and that these "frequently pertained to boundary violations, advertising, and unprofessional language." What was not clear from the data is whether the complaints pertained primarily to professional interactions or whether they included the personal use of social media by psychologists. Another interesting finding from the survey was that the regulatory boards reported minimal use of social media in their own work, with the most frequently utilized means of telecommunication being websites and email. The survey appeared to support the need for the development of guidelines that could be used in the work of regulation and guide the practice of the profession in using social media.

\footnotetext{
${ }^{2}$ The SMTF report and guidelines, including the survey results, has not been finalized at the time this paper is being written.
} 


\section{Social Media Standards and Guidelines}

The SMTF reviewed social media guidelines developed by various health organizations in both the U.S. and Canada, including regulatory bodies. Some of the earliest guidelines were developed by the professions of nursing and medicine. The national organizations representing U.S. state regulatory boards for nurses (National Council of State Boards of Nursing 2011) and physicians (Federation of State Medical Boards 2012) have both published social media guidelines. A number of professional organizations have also published social media guidelines or have made reference to the professional use of social media (e.g., Canadian Counselling and Psychotherapy Association (2019), American Counseling Association (2014), Ohio State Medical Association (2010), American Medical Association (AMA) (2010), Canadian Medical Association (2011), American Psychological Association (2013), Association of Canadian Psychology Regulatory Organizations (2011), Canadian Psychological Association (2006), Australian Psychological Society (2011), National Association of Social Workers, Association of Social Work Boards, Council on Social Work Education, and Clinical Social Work Association (2017)).

Until the work of the ASPPB SMTF, the Oregon Board of Psychology was the only psychology regulatory body that had developed a comprehensive set of social media guidelines (Oregon Board of Psychology 2018). The Oregon Board's guidelines discuss both the relevant ethical considerations that psychologists need to be cognizant of in using social media in their professional practice, and the behavioral expectations of regulation. The guidelines are further enhanced and illustrated by the provision of vignettes involving social media use by a psychologist and a discussion of what an appropriate action might be. A review of the professional literature found a number of publications relevant to the recommended social media guidelines or practices for psychologists (Tunick et al. 2011) and physicians and psychiatrists (Ginory et al. 2012; Peek et al. 2015), (Gabbard et al. 2011), (Chretien and Kind 2013).

In the development of the ASPPB guidelines, the SMTF felt that it would also be useful to provide examples of social media policy and documentation that psychologists could use in their practice. In that regard, the work of Dr. Keely Kolmes (2012) was reviewed and included in the guiding document as a good example of social media policy.

\section{Psychology Ethical Standards}

In approaching the task of guidelines development, the ethical guidance promulgated by the Canadian Code of Ethics for Psychologists (CPA 2017) and the American Psychological Associational Ethical Principals and Code of Conduct (APA 2017) were considered. The codes differ in their conceptualization and articulation of ethical principles and the resolution of ethical issues and are used to varying degrees by regulators in their guidance of the practice of the profession and in the adjudication of complaints against licensees. There is an aspirational quality to the guidance provided in both ethical codes, reflective of the fact that the CPA and the APA are not regulatory organizations. The codes do not directly address the issue of social media use by the profession, leaving "room" for individual interpretation by practitioners and regulatory jurisdictions. From the authors' perspective, this room unintentionally allows for inconsistency in how social media is employed by practitioners, and how its use is regulated. The public interest is perhaps not as well protected where there is a lack of clarity about expectations for practice and conduct, and there is inconsistency in regulation. The ethical codes, however, do outline core ethical concepts common to practice regardless of the modality of service delivery utilized (e.g., informed consent, confidentiality, privacy, boundaries) and it was agreed that these core concepts needed to be addressed in the guidelines being developed.

In the development of the guidelines, the SMTF also reviewed and considered the ASPPB Code of Conduct. The Code of Conduct was intended to augment existing ethical codes and articulates general professional practice standards, is prescriptive, and provides a framework for the adjudication of complaints about the practice of members of the profession for those jurisdictions who choose to adopt it. As the ASPPB has 64 diverse member jurisdictions and itself does not have regulatory oversight, the standards articulated are necessarily general. Further, the standards do not directly address the use of technology in practice or the use of social media by members of the profession.

\section{Legislation and Regulations}

Jurisdictional and national laws relevant to the practice of telepsychology in the U.S., its territories, and Canada, as well as the regulations/bylaws were reviewed. What the SMTF found was that while the legislation in many jurisdictions addresses telehealth/telepsychology practice, they do not specifically address social media use in psychology practice. Possible explanations for this deficiency are: the exponential growth and evolution of the modality making it challenging to capture this within legislation, the dearth of literature on the use of the modality by the profession having the effect of downplaying the reality that this is increasingly becoming a regulatory issue, and possibly the issue of jurisdiction with some regulators viewing psychologists' use of social media as not being within their regulatory jurisdiction due to issues such as the right to freedom of speech or a very circumscribed definition of what constitutes practice, viewing social media use as outside of the definition.

An exception to the lack of regulation for using of telecommunications in the U.S. is offered by the Health Insurance Portability and Accountability Act of 1996 (HIPAA) and its 
regulations. Generally, this law and implementing regulations require that health professionals use secured or encrypted forms of telecommunications when using telecommunications that include client or patient identifying information. The Office of Civil Rights, the enforcement agency for HIPAA, however, has indicated an exception for email is permissible with client informed consent (OCR 2013). This exemption, however, may not be consistent with professional ethical standards or those of regulatory boards (Maheu et al. 2020). In most Canadian jurisdictions, the privacy legislation addresses the issue of health information/personal information, its collection, storage, and access in a general manner and is applicable to all modes of communication and record storage. Three provincial jurisdictions have legislation specific to eHealth (Goodman 2012). The federal legislation, the Personal Information Protection and Electronic Documents Act (PIEPDA), applies to private sector business and establishes the parameters "for how businesses must handle personal information in the course of their commercial activity" (OIPC of Canada 2020). PIEPDA speaks to the issue of electronic data its collection, access, and storage; however, it does not necessarily apply to settings in which health services are provided (Government of Canada 2020).

\section{Drafting Guidelines and the Report}

Once the jurisdictional survey, literature, legal, and ethical code reviews were completed, the SMTF considered how to approach the development of social media guidelines that would be relevant to all of the 64 diverse regulatory jurisdictions in two countries and two different national professional ethical codes. The task was complex as the guidelines had to be general enough to be applicable regardless of the jurisdiction, but pragmatic enough to be of use to both regulators and members of the profession. The format decided upon took its inspiration largely from the guidelines developed and adopted by the Oregon Board of Psychology (2018), which tied its guidelines to ethical code principles, and provided vignettes illustrating the application of the guidelines. The definition of social media adopted in the development of the ASPPB SMTF guidelines was decidedly broad to allow for the inclusion of yet undeveloped future iterations of social media platforms and technologies. Social Media was defined as an "umbrella term" that includes all forms of social interaction via technology as opposed to being viewed as exclusionary and limited to technology platforms marketed specifically for social interaction such as Twitter@ or Facebook@

The following guideline categories were decided upon:

- Confidentiality - this category addresses both the professional and legislated responsibilities to ensure the security of client health and personal information. The considerations of how to achieve this are perhaps more complex when technology is the mode of communication and service delivery.

- Informed consent - this category addresses the necessary process of seeking full client understanding and freely provided consent for services and communications delivered via technology.

- Risk management - this category addresses the responsibility of psychologists to anticipate and mitigate risk when using social media and identifies that ultimately, they are responsible for their social media presence.

- Multiple relationships - this category addresses the importance of ideally avoiding multiple relationships and cautions against overlap between professional and personal social media use/presence.

- Competence - this category addresses the requirement to practice only within the areas in which they have established competency, and to maintain that competency. This duty extends to the use of technology and social media, including ensuring that one has competency in the use of the actual technology and the social media platforms being employed, necessary measures to mitigate risk are understood and taken, and that consideration is given to the appropriateness of the modality for the client and their situation.

- Professional conduct - this category reaffirms the expectation of professionalism in all communications. It addresses issues that are not unique to social media use by the profession but are perhaps of greater significance due to ease of communication via technology, the colloquial nature of communications via this modality, and reality that one's communications may have a broader audience than intended.

- Security of information - this category addresses the issue of the ultimate responsibility for the use of one's social media accounts and reaffirms the responsibility for the safe storage and appropriate access to the information communicated or collected via social media.

- Personal use of social media by licensees - this category addresses the potential that one's personal social media use could impact their professional life, and that maintaining a boundary between professional and personal is important, as is the importance of careful consideration of what one communicates whether that occurs within a professional or personal context.

- Regulatory board use of social media - this category addresses the responsibility of the regulator to control and manage any social media platform utilized in regulatory work and considerations in regard to how to effectively achieve this.

Each SMTF member was assigned the responsibility to draft sections of the SMFT report and guidelines, with each section then having been sequentially reviewed by taskforce 
members. Multiple iterations of the guidelines were created and reviewed and revised over the 20 months of work.

Unique to these guidelines is the inclusion of guidance pertaining to personal social media use by psychologists and to social media use by regulators in the work of regulation. The ethical and conduct issues relevant to each of the guideline categories are identified. Vignettes demonstrating the application of the guidelines are presented to further illustrate their use. A sample social media policy and an informed consent disclaimer are provided to again further articulate the guidelines in practice. The guidelines document recommends the adoption of the guidelines by regulators for use in providing guidance to licensees and in the adjudication of complaints that pertain to the use of social media by licensees. Finally, the SMTF recommended to the ASPPB Board of Directors (BOD) consideration of the development of model regulatory language to add to the ASPPB Model Licensure Act that specifically addresses the use of social media.

The final draft version of the SMTF report and guidelines was submitted to the ASPPB BOD in February 2020. The ASPPB BOD approved the distribution of the draft document for public comment, primarily to the psychology regulatory boards, for a 90-day period from April 29, 2020 to June 28, 2020. The timeline was extended into July to allow response by an ASPPB jurisdiction whose board would not be meeting until mid-July. In August 2020, the SMTF reconvened and reviewed the comments received. Substantive comments about the guidelines identified included the issues of regulatory jurisdiction over personal social media use, the client's right to privacy even when their information is in the public domain, challenges with maintaining a boundary between professional and personal social media use, the importance of cultural competency in using this modality, and equity in access to psychological services. At the time this article was being written, the public comment period had closed and the final draft of the guidelines was being prepared for submission to the ASPPB Board of Directors. It is hoped that the guidelines will be approved for distribution to and use by the ASPPB member jurisdictions who wish to use these.

\section{Discussion}

\section{Commonality across Social Media Guidelines}

Not surprisingly, there appears to be significant commonality among the social media guidelines that have been developed by various health professions in terms of the core ethical concepts covered within them such as informed consent, privacy, confidentiality, professionalism, competency, record keeping, and boundaries, and their application to practice via technology and in particular with social media. Some of the guidelines reviewed were limited to lists of "dos" and "don'ts" and did not clearly appear associated with professional ethical principles. The guidance provided appeared in many cases to be more aspirational and less pragmatic, and as such was not as clear as it could have been in terms of what is expected and is appropriate. The core ethical concepts are not unique to a specific profession, but their application is unique for each profession. The core ethical concepts provide the frame for the guidelines upon which clear statements regarding behavior and action expected of the profession need to be articulated.

Agreement appears to exist that clear guidance from the regulator about what is expected in terms of social media use, and clarity about how the use of this modality will be regulated is important. "With the rapid growth of technology and the transformational changes in how we communicate, there is a professional responsibility to establish norms and guidelines to protect and maximize our commitment to the best interests of our patients while maintaining high professional standards and integrity" (Wiener et al. 2012). Also, agreement appears to exist in terms of core ethical principles that must be considered, and that while these are not unique to a specific profession or to social media use vs. another modality for communication or service delivery, there are complexities unique to using this modality that need to be considered and planned for (e.g., potential for a social media site to be hacked).

\section{The Need for Clarity and Consistency across Jurisdictions}

Without a doubt, psychologists need clarity about regulatory expectations for social media use to be able to successfully navigate this evolving practice landscape. It is also true that the public served by the profession needs to have clarity about what to expect from psychologists using technology and social media in the delivery of psychological services. Regulation of the profession occurs within distinct social, geographic, and political realities and what is legislated and able to be regulated is to an extent reflective of those realities. The challenge in developing guidelines is to strike a balance between the unique jurisdictional realities and the jurisdictional right to autonomy, with the need for greater consistency in the interest of public protection, while at the same time being respectful of professional judgment and autonomy. Complicating the effort is the reality that guidelines must be relevant to practice in two countries with two very distinct cultures. Further, the field as well as the practice of psychology are diverse and to be of value guidelines must be able to capture that diversity. As the use of technology and in particular social media in practice evolves and results in more interjurisdictional practice, it becomes increasingly important that regulators give consideration to the harmonization between jurisdictions of regulatory processes, standards, and philosophy. Greater consistency between jurisdictions is in 
the public interest as well as in the interest of the profession. Greater clarity and consistency about expectations for social media use and how this is regulated mitigates risk, facilitates the expansion of interjurisdictional practice, and ultimately could have a positive impact in terms of increased access to psychological services.

\section{Regulatory Vs. Practitioner Perspectives}

Some of the feedback received in regard to the draft report and guidelines appeared to be reflective of differences in perspective that exist between regulatory bodies and the profession in terms of focus and mandate. Regulatory guidelines and standards necessarily have as the primary focus the protection of the public interest. It is the case that periodically in regulation the interests of the public intersect with those of the profession, such as is the case of title or scope of practice protections within some regulatory legislation. This serendipitous occurrence does not negate the paramount responsibility of regulators to act with intentionality in the interest of the public. At times, the responsibility of public protection does not align with the profession's perspective regarding acceptable professional practice. Actions taken by psychologists must be congruent with the ethics and standards of the profession but must also be contextually relevant and defensible which is "the wheelhouse" of regulation.

An area of potential disagreement about the application the guidelines is whether they apply to a psychologist's personal use of social media. An important question to be asked is "to what extent do regulatory boards have a legitimate interest, obligation and authority to regulate how psychologists use social media when psychologists use it as a private citizen?" Secondary to that is the question "does regulating this activity abrogate the psychologist's right to freedom of speech?" Indisputable is the fact that in much of the world professionals are afforded deference by consumers by virtue of their education and function, and that many consumers will accept without question what is promulgated by professionals. Psychologists may be held to a higher standard of conduct and responsibility than the average citizen, and this is a reality that the profession and regulators will increasingly be faced with as psychologists' scope of influence continues to expand due to the proliferation of social media use by the profession. It has been suggested that it is not a realistic expectation for professionals to "imagine that their personal engagement in social media cannot or will not in any way be linked to their professional" roles (Slobogian et al. 2017). Further, Haeny (2014) discusses that while psychologists "might like their personal lives to be independent from their professional lives, the reality is that their identity as psychologists may never be detached, even outside of a professional context, for those familiar with the psychologist's line of work." In essence, like other professionals, psychologists rightly or wrongly do not have the luxury of "fully removing their psychologist's hat".

The codes of ethics for the profession suggest an implicit "contract with society" and the responsibility within that contract to act with integrity, with primary concern for those served, and with concern for society as a whole (CPA 2017). Without question, the regulatory responsibility is to protect the public and to mitigate their risk of harm as a result of the misconduct and incompetence of members of the profession. Regulation historically has not had a role in guiding the private lives of members of the profession, and some would argue that it should never have this role. However, where there is an intersection of psychologists' professional and private lives, there may be a responsibility for regulators to act. Social media use may increase the likelihood of such an intersection. An example of this might be if one were to post negative comments to their private Facebook page about client populations they serve, and this were to become public. The argument could be made that the psychologist never intended for their thoughts to become public and therefore the regulator should not become involved. Cork and Grant (2016) note that in using social media there is "no guarantee that private will not become public" given the modality. A contrary argument, however, is that if this leads the public to view the profession negatively or to feel "lesser" as a result of these comments it may be quite appropriate for the regulator to become involved. There are undoubtedly significant benefits to social media use in practice and research contexts, however, it is noted that professionals need to be cognizant for the blurring of boundaries between their professional and private lives. Intentional management of risk is necessary to ensure that confidence and privacy are maintained (Denecke et al. 2015).

This issue is complicated and likely to remain a challenge for regulatory boards due to a lack of consensus about how to manage such complaints, and whether such complaints should even be considered. Nonetheless, regulatory boards will be called upon to respond to complaints where licensees have publicly made statements in social media that reflect negatively upon the public's perception of the profession.

\section{Guidelines Vs. Standards}

Consideration was given by the SMTF as to whether the final work product should be in the form of guidelines or whether it should be in the form of standards. Guidelines typically are aspirational and are seen as recommendations, as opposed to standards which are prescriptive and seen as mandatory (APA 2002). The need for clear rules vs. leaving room for individual interpretation when it comes to the issues of regulation and public protection is a topic of debate that is difficult to resolve. Guidelines by their very nature tend to be more aspirational, and to encourage the development and use of one's 
professional judgment. Guidelines, however, may not be specific enough for some to assist them in mitigating risk and may not allow for full protection of the public interest. Conversely, standards are prescriptive, are often codified within legislation, and provide clear rules. Standards, however, while enforceable, are difficult to make flexible enough to capture the continually evolving nature of the modality and may not allow for the contextual issues of individual situations to be considered.

Challenges to establishing standards as opposed to guidelines include:

- A prescriptive approach does not and cannot take into account the diversity and uniqueness of the contexts in which practice and in particular ethical dilemmas occur.

- A prescriptive approach does not encourage the use of professional judgment and inadvertently may create greater risk for the client and for the professional.

- Standards to be enforceable must be codified within legislation, and achieving legislative amendment is a challenge that can create unintended consequences such as other areas of the legislation being open to challenge.

- As ASPPB represents 64 diverse regulatory jurisdictions that span 2 countries, whatever was created needed to be broad enough to be applicable to all, and to be respectful of jurisdictional autonomy thus decreasing the possibility of only limited uptake.

The challenge facing the SMTF was to develop a document that could be used in regulation, specifically in providing practice expectations and in the adjudication of complaints, while not being so prescriptive as to render the document limited in its applicability. The SMTF chose to establish guidelines as opposed to standards and attempted to avoid being overly restrictive in defining the guidelines to allow for some degree of discretion and professional judgment for their application on a case by case basis. The social media guidelines developed by the SMTF are intended to provide guidance in applying the current national ethical standards in Canada and the U.S. and its territories rather than creating new social media standards.

\section{The Need for Training and Education in Social Media Uses}

Training and education in telepsychology, including uses of social media, typically are not included in psychology graduate program curriculums. Psychologists providing telepsychology and using social media usually have been dependent upon whatever training and education they have personally chosen to obtain, if any. To compound this, currently, there is no consensus about what telepsychology competencies ought to be included in psychology training and education although there are efforts to define such competencies and education (Maheu et al. 2020; Perle 2020). Psychologists and those training to be psychologists are increasingly providing telepsychology services, especially since the COVID-19 pandemic, making it critical that educational programs include telepsychology competency educational and training experiences. As the practice of psychology increasingly includes telepsychology and social media, regulation will need to evolve to define what competency in using these modalities looks like from a behavioral perspective and will need to determine how to evaluate that competency.

\section{Appropriateness of the Modality's Use}

The authors believe that the appropriateness of social media use in the provision of psychological services to a particular client or client group is an essential consideration. The ethical standards of the profession call on members of the profession to ensure that the modality of service delivery employed is appropriate to those being served. Cultural humility and an understanding of the culture of those being served are essential in determining appropriateness, as is the acknowledgement that the use of technology may not be appropriate for all groups whether that be due to issues about access to technology, client comfort or competency with technology, service needs, provider competency, etc.

\section{Limitations of the Guidelines}

The development of the social media guidelines was conducted with the recognition that no one set of guidelines can fully address all situations and totally eradicate risk. Also understood was that the guidelines need to be treated as a "living document" and as such requires regular review and revision as the modality and its use evolve. The authors believe that it is important to consider the limitations of the guidelines and to use these to inform future iterations and needed work within regulation.

A general lack of agreement exists as to what constitutes social media. There are multiple definitions currently in use which confounds the issue of regulation. This lack of agreement around a definition presents a challenge to providing behaviorally grounded guidance, and in determining the extent to which regulatory boards should regulate the use of the modality. The practical application of guidelines is somewhat subjective and necessarily dependent upon the context in which the question of how to proceed is situated. This is a necessary reality given the diversity of the practice of psychology, however, there appears to be a lack of agreement within the profession and regulation about what constitutes "appropriate behavior" in the use of social media and this is problematic. Establishing at least regulatory consensus about what is appropriate behavior is important. Another limitation of the guidelines is that the boundary between professional and personal social media use was not clearly delineated. Issues of 
boundaries, privacy, and the "right" to free speech need to somehow be addressed going forward.

A singular focus on the public interest may be key to sorting through these issues. A final limitation to the guidelines is that of voluntary adoption which was unavoidable given the guidelines were developed by an association of regulators, and that there continues to be significant heterogeneity within the regulation of the profession. While the differences within regulation between jurisdictions is not likely to be easily resolved, it is important to continue to push for more similarity in regulation in the interest of the public, and in light of the pressures both political and social to remove barriers to practice and to increase public access to qualified health services.

\section{Conclusions}

Social media is a rapidly evolving form of telecommunications that is increasingly being used by psychologists. This has resulted in psychology regulatory boards increasingly being confronted with complaints in which social media use is an issue and regulatory boards are being challenged to determine what is appropriate use from inappropriate use. In the absence of social media guidelines or standards specific to the profession, regulatory boards have relied primarily upon the ethical codes promulgated by the profession for determining how to judge the appropriateness of its uses. In response to the need for profession-specific guidance and the need for clarity and consistency in regulating social media uses, the ASPPB is working to establish a set of social media guidelines that are designed to work in conjunction with the profession's ethical standards and principles for use by its member boards and members of the profession. It is believed that these guidelines will help improve the quality of care and better protect the public. Given that social media continues to rapidly change, it is recognized that the applicability and relevance of the guidelines may change, and as such they will need to be reviewed and revised as the field evolves.

\section{Compliance with Ethical Standards}

Disclaimer The contents of this paper represent the opinions and views of the authors and not those of the organizations with which they are affiliated.

\section{References}

American Counseling Association (ACA). (2014). ACA code of ethics. Retrieved from https://www.counseling.org/resources/aca-code-ofethics.pdf

American Medical Association (AMA). (2010). Professionalism in the Use of Social Media. Retrieved at https://www.ama-assn.org/ delivering-care/ethics/professionalism-use-social-media
American Psychological Association. (2002). Criteria for practice guideline development and evaluation. American Psychologist, 57(12), 1048-1051. https://doi.org/10.1037//0003-066X.57.12.1048.

American Psychological Association. (2013). Guidelines for the practice of telepsychology. http://www.apa.org/practice/guidelines/ telepsychology.aspx

American Psychological Association. (2017). Ethical principles of psychologists and code of conduct. Retrieved at https://www.apa.org/ ethics/code/ethics-code-2017.pdf

American Psychological Association. (2020). Notice of developmentproposed guidelines for optimal use of social media in professional psychological practice. Retrieved at https://www.apaservices.org/ practice/ce/guidelines/practice-guidelines

Association of Canadian Psychology Regulatory Organizations. (2011). Model standards for telepsychology service delivery. Retrieved at https://acpro-aocrp.ca/wp-content/uploads/2020/03/ACPROModel-Standards-for-Telepsychology-Service-Delivery.pdf

Association of State and Provincial Psychology Boards. (2020) Mission statement. Retrieved at https://www.asppb.net/general/custom.asp? page $=$ What_is_ASPPB

Australian Psychological Society. (2011). Guidelines for providing psychological services and products using the internet and telecommunications technologies. https://web.archive.org/web/*/https:// aaswsocialmedia.wikispaces.com/file/view/EG-Internet.pdf

Canadian Counseling and Psychotherapy Association. (2019). Guidelines for uses of technology in counselling and psychotherapy. Retrieved at https://www.ccpa-accp.ca/wp-content/uploads/2019/04/ TISCGuidelines_Mar2019_EN.pdf

Canadian Medical Association. (2011). Social media and Canadian physicians: issues and rules of engagement. Retrieved at http:// policybase.cma.ca/dbtw-wpd/Policypdf/PD12-03.pdf

Canadian Psychological Association. (2006). Draft ethical guidelines for psychologists providing psychological services via electronic media. Retrieved at https://cpa.ca/docs/File/Ethics/Draft_Guidelines EServices_31Oct2013.pdf

Canadian Psychological Association. (2017). Canadian code of ethics for psychologists. Retrieved at https://cpa.ca/aboutcpa/committees/ ethics/codeofethics/

Canadian Psychological Association. (2020). Interim ethical guidelines for psychologists providing psychological services via electronic media. Retrieved at https://cpa.ca/docs/File/Ethics/CPAetherapyGuidelinesUpdate2020.pdf

Chretien, K., \& Kind, T. (2013). Social media and clinical care ethical, professional, and social implications. Circulation, 127, 1413-1421.

Cork, N. A., \& Grant, P. B. (2016). Blurred lines: the general medical council guidance on doctors and social media. Clinical Medicine, 16(3), 219-222.

Denecke, K., Bamidis, P., Bond, C., Gabarron, E., Househ, M., Lau ,A. Y. S., Mayer, M. A., Merolli, M., Hansen, M. (2015). Ethical issues of social media usage in healthcare. IMIA Yearbook of Medical Informatics, 137-147.

Drude, K. (2016) E-mail and texting experiences: Ohio Board of Psychology, presented May 5, 2016 at association of state and provincial psychology boards meeting, Anchorage, Alaska.

Federation of State Medical Boards. (2012). Model policy guidelines for the appropriate use of social media and social networking in medical practice. Retrieved at http://www.fsmb.org/siteassets/advocacy/ policies/model-guidelines-for-the-appropriate-use-of-social-mediaand-social-networking.pdf

Gabbard, G., Kassaw, K., \& Perez-Garcia, G. (2011). Professional boundaries in the era of the Internet. Academic Psychiatry, 35, $168-174$.

Ginory, A., Mayol Sabatier, L., \& Eth, S. (2012). Addressing therapeutic boundaries in social networking. Psychiatry, 75(1), 40-48.

Goodman, P. (2012). Electronic health record regulation in Canada: What the patient experience reveals about the pursuit of legislative 
harmonization, Master's Thesis, University of Western Ontario, London, Ontario.

Greysen, R., Chretien, K., Kind, T., Young, A., \& Gross, C. (2012). Physician violations of online professionalism and disciplinary actions: a national survey of medical boards. Journal of American Medical Association, 307(11), 1141-1142.

Haeny, A. M. (2014). Ethical considerations for psychologists taking a public stance on controversial issues: the balance between personal and professional life. Ethics and Behavior, 24(4), 265-278.

Kolmes K (2012). Social media: what's your policy? APA Good Practice Spring/Summer.

Maheu, M., Drude, K., Merrill, C., Callan, J., \& Hilty, D. (2020). Telebehavioral health: foundations in theory and practice for graduate learners. Cognella Inc..

National Association of Social Workers, Association of Social Work Boards, Council on Social Work Education, \& Clinical Social Work Association. (2017). Standards for technology in social work practice. Retrieved at https://www.aswb.org/wp-content/uploads/ 2013/10/TechnologySWPractice.pdf

National Council of State Boards of Nursing (NCSBN). (2011). White paper: a nurses guide to the use of social media, Retrieved at https:// www.ncsbn.org/11_NCSBN_Nurses_Guide_Social_Media.pdf

Office of Civil Rights. (2013). "Does the HIPAA Privacy Rule permit health care providers to use e-mail to discuss health issues and treatment with their patients?" Retrieved at https://www.hhs.gov/hipaa/ for-professionals/faq/570/doeshipaa-permit-health-care-providersto-use-email-to-discuss-health-issues-with-patients/index.html

Office of the Information and Privacy Commissioner (OIPC) of Canada website. (2020). Retrieved at https://www.priv.gc.ca/en/privacytopics/privacy-laws-in-canada/the-personal-information-protectionand-electronic-documents-act-pipeda/

Ohio State Medical Association. (2010). Social networking and the medical practice: guidelines for physicians, office staff and patients. Journal of the Ohio State Medical Association, 103(10), 517-526.
Oregon Board of Psychology. (2018). Social media guidelines. Retrieved at https://www.oregon.gov/Psychology/Documents/SMC_FINAL 10-2-18.pdf

Peek, H., Richards, M., Muir, O., Chan, S., Caton, M., \& MacMillan, C. (2015). Blogging and social media for mental health education and advocacy: a review for psychiatrists. Current Psychiatry Reports, $17,88$.

Perle, J. (2020). Introduction to telehealth for clinical psychologists: a novel course designed to improve general knowledge and handson expertise with technology-based modalities. Journal for Technology in Behavioral Science. https://doi.org/10.1007/s41347020-00147-6.

Government of Canada website (2020). The Personal Information Protection and Electronic Documents Act (PIPEDA). Retrieved at https://www.priv.gc.ca/en/privacy-topics/privacy-laws-in-canada/ the-personal-information-protection-and-electronic-documents-actpipeda/

Slobogian, V., Giles, J., \& Rent, T. (2017). \#Boundaries: when patients become friends. Canadian Oncology Nursing Journal, 27(4), 394 396.

Tunick, R., Mednick, L., \& Conroy, C. (2011). A snapshot of child psychologists' social media activity: professional and ethical practice implications and recommendations. Professional Psychology: Research and Practice, 42(6), 440-447.

von Muhlen, M., \& Ohno-Machado, L. (2012). Reviewing social media use by clinicians. Journal of the American Medical Informatics Association, 19(5), 777-7781.

Wiener, L., Crum, C., Grady, C., \& Merchant, M. (2012). To friend or not to friend: The use of social media in clinical oncology. Journal of Oncology Practice, 8(2), 103-106.

Publisher's Note Springer Nature remains neutral with regard to jurisdictional claims in published maps and institutional affiliations. 